\title{
A temática saúde nos documentos internacionais sobre esporte e lazer entre os anos de 1964 e 1985
}

\author{
Alessandro Barreta Garcia \\ Mestre pela Universidade Nove de Julho-SP e Doutorando em \\ Educação Física pela Universidade São Judas Tadeu-SP \\ 凹alessandrogarcia@hotmail.com \\ Rui Anderson Costa Monteiro \\ Doutor em Educação Física pela Universidade Nove de Julho-SP \\ $\triangle$ profruianderson@gmail.com \\ Almir de França Ferraz \\ Mestre (Doutorando) em Educação Física pela Universidade São Judas Tadeu-SP \\ 凶ferraz7777@gmail.com \\ Erinaldo Luiz de Andrade \\ Doutor em Educação Física pela Universidade São Judas Tadeu-SP \\ $\square$ erinaldo_andrade@uol.com.br \\ Aylton Figueira Junior \\ Doutor em Educação Física pela Universidade Estadual de Campinas- SP \\ Docente da Universidade São Judas Tadeu-SP \\ 凹aylton.junior@saojudas.br
}

\section{Resumo:}

O tema saúde sempre suscitou curiosidades de muitos pesquisadores. Sendo ela uma temática de grande importância, diferentes trabalhos são expostos com variados pontos de vistas e críticas. $\mathrm{Na}$ área da educação física não é diferente, e essa discussão se arrasta por muitos anos em um cenário de rediscussão constante. Nesse contexto, muitas críticas acabam por surgir, uma delas é a ideia de que a saúde não foi amplamente debatida no período dos governos militares e pouco havia de documentação a esse respeito. A pergunta de partida do presente estudo é: não havia uma preocupação mais ampla com a saúde, bem como, documentos que tratassem dessa temática no âmbito da educação física escolar e do esporte? O objetivo da pesquisa consistiu em identificar, analisar e sintetizar documentos relacionados à saúde com ênfase no esporte e lazer/educação física brasileira no período de 1964 a 1985. Os documentos utilizados a partir da indicação da bibliografia do professor Manoel Gomes Tubino. A análise dos documentos fundou-se no item "conteúdos sobre saúde" à luz do conceito de saúde de 1946. Foi possível entender que as práticas esportivas na sociedade e na escola estavam alinhadas aos ideais de prevenção da saúde por meio do desenvolvimento dos aspectos físico, social e mental. Dessa forma, os resultados parecem contradizer o pensamento de parcos documentos abordando o fomento à saúde no período de 1964-1985, seja na escola ou na sociedade de forma geral.

Palavras-chave: Documentos internacionais, Educação física, Promoção da saúde, Esporte. 


\title{
The thematic health in international documents on sport and leisure enters the years of 1964 and 1985
}

\begin{abstract}
:
The subject health always excited curiosities of many researchers. Being it a thematic one of great importance, different works are displayed with varied critical points of view and. In the area of the physical education it isn't different, and this quarrel if it drags per many years in a scene of constant rediscussion. In this context, many critical ones finish for appearing, one of them is the idea of that the health widely was not debated the period of the military governments, and little it had of documentation to this respect. The question of departure of the present study is: it did not have an ampler concern with the health, as well as, documents that dealt with this thematic one in the scope of the pertaining to school physical education and of the sport? The objective of the research consisted of identifying, analyzing and to synthesize documents related to the health with emphasis in the sport and leisure/Brazilian physical education in the period of 1964 the 1985. The documents used from the indication of the bibliography of the teacher Manoel Gomes Tubino. The analysis of documents established in the item "contents on health" to the light of the concept of 1946 health. It was possible to understand that the practical sportive in the society and the school were lined up to the ideals of prevention of the health by means of the development of the aspects physical, social and mental. Thus, results they seem to contradict the thought of sparing documents approaching the promotion to the health in the period of 1964-1985, either in the school or the society of general form. Keywords: International documents, Sport, Promotion of the health, Physical education.
\end{abstract}

\section{La temática salud en los documentos internacionales sobre deporte y ocio entre los años 1964 y 1985}

\section{Resumen:}

El tema de la salud siempre ha despertado la curiosidad de muchos investigadores. Al ser un tema de gran importancia, se exponen diferentes obras con diversos puntos de vista y críticas. En el área de educación física no es diferente, y esta discusión se ha prolongado durante muchos años en un escenario de constante discusión. En este contexto, eventualmente surgen muchas críticas, una de ellas es la idea de que la salud no fue ampliamente debatida durante el período de los gobiernos militares y que había poca documentación al respecto. La pregunta inicial del presente estudio es: ¿no había una preocupación más amplia con la salud, así como, documentos que trataran este tema en el contexto de la educación física escolar y el deporte? El objetivo de la investigación fue identificar, analizar y sintetizar documentos relacionados con la salud con énfasis en el deporte y el ocio / educación física brasileña desde 1964 hasta 1985. Los documentos utilizados a partir de la indicación de la bibliografía del maestro Manoel Gomes Tubino. El análisis de los documentos se basó en el ítem "contenido de salud" a la luz del concepto de salud de 1946. Era posible comprender que las prácticas deportivas en la sociedad y en la escuela estaban alineadas con los ideales de prevención de la salud a través del desarrollo de aspectos físicos, social y mental. Por lo tanto, los resultados parecen contradecir la idea de documentos escasos que aborden la promoción de la salud en el período 19641985, ya sea en la escuela o en la sociedad en general.

Palabras clave: Documentos internacionales, Educación física, Promoción de la salud, Deporte.

\section{INTRODUÇÃO}

O interesse pelas questões de saúde e educação em saúde seja na escola, em clubes ou nos demais espaços, não é recente. No Brasil, como descreve Pelicioni e Pelicioni (2007), 
remonta os anos do período colonial. As autoras ressaltam que na época de 1813 já existia uma disciplina denominada de higiene no currículo da Faculdade de Medicina do Rio de Janeiro. Em 1833 tal disciplina muda seu nome para higiene e história da medicina, e essas mudanças constantes ocorreram até o formato das atuais políticas e modelos de cursos na área da saúde que vislumbramos.

Na pesquisa de Da Costa, Souza Santos e Góis Junior (2014) foram estudadas 5 teses da época imperial brasileira a respeito da educação física e sua relação com a higiene. Os autores concluíram que a ginástica era defendida nas escolas por sua eficiência na disseminação de hábitos saudáveis de forma moderada e monitorada por mestres capacitados. Na República Velha e na Era Vargas o interesse pela saúde só cresceu, tendo nesse período diversas discussões de ordem sanitarista e higienista. Segundo Pelicioni e Pelicioni (2007), a partir da Segunda Guerra Mundial, programas da Organização Mundial da Saúde (OMS) apresentaram novos caminhos e discussões, além de intensificarem os debates em torno do tema.

Pelicioni e Pelicioni (2007) fazem uma crítica pontual aos anos que se seguiram após 1964: "A atenção à saúde era feita principalmente por instituições privadas seguindo e reforçando o modelo biomédico baseado em ações curativas" (p. 325). As pesquisadoras nos levam a entender que não havia, ou eram poucas, as medidas em termos de promoção e prevenção. Nico Monteiro e Bizzo (2015) defendem a ideia que no período de 1964 a 1985 existiam poucas iniciativas para melhorar a saúde da população, nos levando a crer que a saúde era vista de forma superficial tendo como foco os processos terciários, isto é, quando o cidadão já estava acometido por alguma patologia.

Apesar dessas críticas, órgãos internacionais a partir da década de 1960 iniciaram seus posicionamentos em relação ao esporte na escola e o esporte de massa para a sociedade, segundo o Manifesto Mundial do Esporte ou Manifesto Mundial do Desporto de 1964. Tubino (1987) observou que tal documento trouxe ampla explicação inerente ao esporte-educação, esporte de lazer e esporte de alto rendimento. Para o esporte-educação, a integração de conteúdos era primordial, estes, definiram objetivos que ajudavam na formação integral do cidadão (nessa formação integral se incluía a saúde como um dos componentes essenciais), no esporte de lazer, esperava-se que o tempo livre pudesse ajudar na saúde, já para o esporte de alto rendimento, o intuito era atingir o máximo das capacidades e habilidades com a 
finalidade de competir. Entendemos que nenhuma dessas perspectivas do esporte estavam apartadas dos pressupostos da saúde.

Tubino (1987) também analisa a Carta Européia do Esporte para Todos (1975), ele afirma a existência de relação com a campanha que se iniciava na Noruega, depois na Alemanha; Suécia; Bélgica; Estados Unidos e Canadá (estes países desenvolveram campanhas de prevenção em saúde por meio de práticas esportivas e de atividades físicas em larga escala). 0 autor também pesquisou sobre a Carta Internacional da Educação Física e Desportos (1978) e seus pressupostos relacionados ao esporte e a saúde.

Dito isto, elaboramos a seguinte indagação: não havia realmente uma preocupação mais ampla com a saúde, bem como, documentos que tratassem dessa temática direta ou indiretamente no período de 1964-1985? Apoiado em nossa pergunta, o objetivo desta pesquisa foi identificar, analisar e sintetizar os documentos relacionados à saúde com ênfase no esporte/educação física voltados para a sociedade de forma geral e à escola. A relevância deste trabalho se pauta no interesse pela temática e concomitante necessidade de se entender as diferentes ações promotoras de saúde na escola e na sociedade sob a perspectiva dos conteúdos e estratégias do esporte, considerando a importância dos estudos a subsidiar futuros programas de prevenção em saúde na escola e nos demais contextos da sociedade.

\section{METODOLOGIA}

Para a pesquisa em questão foram selecionados quatro documentos sugeridos por Tubino (1987) com as seguintes temáticas:

- Manifesto Mundial do Desporto (1964) de Noel-Baker - documento clássico sobre a tríade; desporto na escola, desporto nos tempos livres e desporto de alta competição.

- Manifesto Mundial da Educação Física (1971) - apresenta as linhas gerais sobre a importância do esporte para a sociedade e para a escola.

- $\quad$ Carta Européia do Esporte para Todos (1975) - trata da importância da massificação do esporte. 
- Carta Internacional da Educação Física e Desportos (1978) - refere-se ao esporte dentro do contexto integral (que se refere aos aspectos sociais, biológicos, culturais, éticos e filosóficos).

Esses documentos foram selecionados com base em nossa problemática a partir das críticas expostas por Pelicioni e Pelicioni (2007) e Nico Monteiro e Bizzo (2015) que alegam ter no período de 1964 a 1985 poucos estudos e documentos relacionados à prevenção e educação em saúde.

Seguindo as orientações de Ranke (2015) sobre o método documental, a ideia pautouse na análise das fontes primárias, neste caso, os documentos internacionais traduzidos no Brasil e utilizados como referência para o desenvolvimento de políticas públicas ao esporte e à promoção da atividade física voltada à saúde como atestam Tubino (1987) e Moreira (2013).

A análise qualitativa documental teve como fundamentação os autores Samara e Tupy (2010) que sugerem a identificação de itens de análise, que neste trabalho consistiu nos “conteúdos sobre saúde". Salientamos que o conceito de saúde se modificou ao longo do tempo e hoje existem diversos entendimentos em torno desta temática, porém, observando o tempo histórico adotado em nossa revisão, utilizamos a definição da Organização Mundial da Saúde (OMS, 1946) "A saúde é um estado de completo bem-estar físico, mental e social, e não consiste apenas na ausência de doença ou de enfermidade" (p. 1). Este conceito foi difundido durante os anos de 1964-1985, portanto, acreditamos ser apropriado para a nossa análise.

Leopold von Ranke, considerado um dos precursores da moderna pesquisa documental, entende que pesquisar requer dois itens importantes: amor pelo objeto de pesquisa e a respectiva identificação do nexo causal (RANKE, 2015), pautados nesta afirmação, esclarecemos que o estudo se contextualiza no cenário da Educação Física, da Atividade Física e Saúde e da Educação em Saúde, áreas inerentes à formação e estudo dos respectivos autores.

\section{RESULTADOS}

A suposta superficialidade no trato da saúde durante os anos de 1964 a 1985

Pelicioni e Pelicioni (2007) esclarecem que a preocupação com a saúde é bem antiga e que no Brasil ela começa com a vinda da Família Real portuguesa em 1808. Essa preocupação 
ocorreu tanto na Colônia como no Império, mas como destacamos na pesquisa de Da Costa, Souza Santos e Góis Junior (2014), uma série de estudos sobre ginástica e higiene tiveram nos anos do Império uma repercussão maior. De Melo e Peres (2014) contextualizam este período em função da união entre; ginástica, medicina e saúde e os vinculam à prática de ginástica aos benefícios relacionados ao tratamento de moléstias como as doenças crônicas do coração. Da República Velha à Era Vargas os estudos e as preocupações se intensificaram com a consolidação dos chamados movimentos higienistas. Durante o regime militar (1964-1985), essa preocupação com a saúde teria ficado em segundo plano.

Analisando alguns documentos, Nico Monteiro e Bizzo (2015) alegam pouca documentação específica, sejam oficiais ou de contexto geral em âmbito nacional, a respeito da saúde na escola. Os autores citam a necessidade dessa discussão a partir da Lei de Diretrizes e Bases de $1971^{1}$, pois este documento previu que as temáticas em saúde deveriam fazer parte do cenário escolar como programas de saúde. "Será obrigatória a inclusão de Educação Moral e Cívica, Educação Física, Educação Artística e Programas de Saúde nos currículos plenos dos estabelecimentos de lo e $2^{\circ}$ graus, observado quanto à primeira o disposto no Decreto-Lei n. 369, de 12 de setembro de 1969" (BRASIL, 1971, Art. 7º).

Nico Monteiro e Bizzo (2015) ainda lembram que a concepção de saúde da década de 1970 pouco considerou os aspectos sociais e culturais. Também afirmam que a saúde era tratada como uma condição a ser conquistada individualmente, sendo a responsabilidade do Estado limitada às ações desenvolvidas no âmbito escolar, porém, como já apresentamos anteriormente, sem documentação de abrangência nacional ou alcance dos professores.

É preciso notar que quando Pelicioni e Pelicioni (2007) e Nico Monteiro e Bizzo (2015) apontam para a falta de documentos oficiais que tratassem da temática saúde, os autores desconsideram, por exemplo, um conjunto de outros documentos, embora não oficiais, bastante relevantes, já que a circulação e alcance nacional entre as instituições e profissionais os colocavam em situação de destaque, somado ao potencial de difusão de desenvolvimento de ideias relacionadas ou correlacionadas à melhoria da saúde.

\footnotetext{
${ }^{1}$ Monteiro, González e Garcia (2011) e Monteiro (2012) destacam que a Lei de Diretrizes e Bases 5692/71 (LDB), de 11 de agosto 71, teve sua abrangência na Educação Básica, na época ensinos de $1^{\circ}$ e $2^{\circ}$ graus. Por isso, diferencia-se das Leis de Diretrizes e Bases da Educação Nacional (LDBEN) 4.024/61 e a atual 9.394/96 extensiva a toda educação brasileira em níveis, modalidades e sistemas de ensino.
} 
Em função dessa conjuntura é que vamos nos atentar aos documentos não oficiais (não governamentais), mas difundidos no âmbito internacional que certamente influenciaram muito as ações direcionadas à saúde nas aulas de educação física escolar. Ainda assim, é preciso ressaltar que apesar de não oficiais, tais documentos foram divulgados também por canais oficiais como as publicações da Revista de Educação Física e Desportos do MEC que propagavam os conhecimentos em âmbito nacional.

Guedes e Guedes (1994) colocam que a prática desportiva durante o regime militar era desenvolvida segundo critérios de performance atlética. Os autores advogam que as aulas de educação física serviam aos pressupostos competitivos e de formação do atleta. Os autores parecem ter ignorado os pressupostos das aulas de educação física direcionados à aptidão física e a saúde como previa o próprio currículo da educação física na época (SÃo PAULO, 1973).

Como exposto acima, e sabendo que vários documentos influenciam, mesmo que de forma indireta, programas de saúde na escola/sociedade, acreditamos ser necessária a busca pelos documentos sugeridos por Manoel Gomes Tubino e relevante a reflexão para melhor entender este assunto.

\section{Manifesto mundial do desporto (1964)}

O Manifesto Mundial do Desporto de autoria de Noel-Baker (1964), publicado pelo Conseil Internationale d'Education Physique et Sport (CIEPS) começa definindo o esporte como jogo que envolve um ou mais participantes com a finalidade de competição. 0 esporte está associado historicamente à educação física na escola e inter-relacionado com a saúde por desenvolver as capacidades físicas e motoras. Além da escola, é na família, segundo o Manifesto Mundial do Desporto, que o esporte se desenvolve com múltiplas finalidades, entre elas a melhora da saúde (Noel-Baker, 1964).

O homem desde a Pré-História busca se humanizar e o esporte é um dos meios mais eficientes para tal propósito (se humanizar também engloba ter mais saúde). Como afirma Gasset (1991): 
Eis aqui que o animal é atécnico: contenta-se em viver e viver com o que é objetivamente necessário para o simples existir. Sob o ponto de vista do simples existir, o animal é insuperável e não precisa da técnica. Mas o homem é homem porque existir, para ele, pressupõe, naturalmente e sempre, bem-estar; por isso ele é a nativitate técnico criador do supérfluo. Homem, técnica e bem-estar são, em última análise, sinônimos (GASSET, 1991, p. 17).

Ele é autoconhecimento, saúde e vida, claro, quando afastado do alto rendimento. 0 esporte é nesse contexto a maior prova de conduta humana na direção do progresso e do desenvolvimento físico, psicológico, social e mental, tal como a própria definição de saúde.

Noel-Baker (1964) assinala o esporte como direito, aí está a maior prova de sua beleza tradicional e de sua necessidade. Precisamos do esporte assim como precisamos de educação, pois, aliás, o esporte também é parte de um sistema educacional. Precisamos do esporte, assim como precisamos de saúde, pois este também pode se relacionar com aspectos da saúde. Tudo que é bom e proporciona satisfação deve ser preservado e o esporte se encaixa muito bem nessa ideia, defende Noel-Baker. Para deixar mais clara à relação que o autor faz do esporte com a saúde, ele divide a prática esportiva em três: desporto educação, desporto nos tempos livres e desporto de alta competição. Entendemos que cada uma dessas dimensões se relaciona com a saúde a partir da observação de seus objetivos, locais, modelos e intensidade.

\section{Desporto na escola}

Sobre o desporto na escola, Noel-Baker (1964) defende que o esporte é e sempre foi indispensável, é claro que precisamos discutir o como, mas ele é sem dúvida algo necessário. Como formador do caráter, o esporte é vital para o desenvolvimento harmonioso e saudável. Por isso, sua prática por toda vida é indispensável. o corpo e a mente sempre analisados dicotomicamente só nos servem didaticamente, fora isso, sabemos com perfeição que desde Aristóteles estes componentes são inseparáveis.

O desporto contribui para o desenvolvimento físico harmonioso da criança, prepara-a fisiologicamente para o esforço, auxilia o seu equilíbrio físico e psíquico, participa na formação da sua vontade, do seu caráter, e favorece a sua adaptabilidade social (NOEL-BAKER, 1964, p. 70). 
Defender o esporte é defender a família que junta pratica diversos esportes como um conjunto de tradições de extrema importância mais para a humanidade. Algo como a religião, como as mais belas instituições e tradições de uma sociedade. Noel-Baker defende, como vimos, um equilíbrio fisiológico, psíquico e social, nesse sentido, este é o próprio conceito de saúde que define o nosso item de análise. Observamos que as relações entre esporte e saúde ocorrem tanto no currículo da década de setenta (SÃO PAULO, 1973) como no currículo atual da educação física do Estado de São Paulo (SÃO PAULO, 2009), nesse último currículo as relações se encontram no eixo temático: corpo, saúde e beleza.

\section{Desporto nos tempos livres}

Quando o assunto é o desporto em tempo livre, Noel-Baker (1964) advoga que afastar os homens da inatividade física é o mais saudável. As atividades devem levar em conta a idade e sexo dos participantes, os cuidados médicos também são essenciais para tais práticas. As atividades são recomendadas por toda vida, desde que se tenha saúde e vontade para tal realização. Logo, praticar esporte pela vida toda é um dos comportamentos mais esperados para se contribuir com a saúde. Conforme Ferreira, e Najar (2005) o programa Agita São Paulo tem tido um papel fundamental para o incentivo às práticas de atividades físicas, entre estas, as esportivas.

\section{O desporto de alta competição}

Por fim, o Manifesto Mundial do Desporto de Noel-Baker (1964) apresenta considerações sobre o desporto de alta competição. Nele se expressa o mais alto nível de preparação física, psíquica e social. Para este, é necessário empenho em tempo integral, dessa forma, trabalhos concorrentes com o desporto não são adequados. O importante aqui é perceber que quando se fala em alto rendimento são afastadas as suas relações com a saúde, isto, provavelmente porque o alto rendimento coloca os praticantes de esporte em grande risco de lesão. 


\section{Carta européia do esporte para todos (1975)}

Documento redigido em 1975, em Bruxelas (originalmente de 1972), a Carta Européia do Esporte para Todos (1985) abre uma perspectiva de extrema relevância para a educação física mundial e brasileira. Já de início reconhecem os ministros europeus, responsáveis pelo desporto, que este é fundamental para o desenvolvimento de uma consciência de lazer, reconhecendo, deste modo, a necessidade de oferecer o esporte a uma camada da população cada vez mais extensa.

Desde 1966 que este conceito de esporte para todos é o conceito norteador de uma educação física eficaz para toda população, assim: “O Desporto deve ser parte integrante dos programas de desenvolvimento cultural, educativo, social e de saúde" (CARTA EUROPÉIA DO ESPORTE PARA TODOS, 1985, p. 63). Ficando dessa forma explícita a vontade de se incentivar a prática esportiva com fins de desenvolvimento harmonioso e saudável. Neste documento é clara a ligação direta com a ideia de aprimoramento da saúde como direito de todos por meio do esporte tal como expressa a Constituição da República Federativa do Brasil, no Art. 217 (BRASIL, 2011), que define o desporto como direito de todos tendo o poder público a missão de incentivar sua promoção para o bem social.

\section{Manifesto mundial de educação física (1971)}

No Manifesto Mundial de Educação Física (1971), desenvolvido pela (FIEP) Federação Internacional de Educação Física é plausível admitirmos que o embasamento que a educação física brasileira seguia durante o regime militar (1964-1985) estava pautado em um discurso de formação do cidadão a partir do corpo saudável e equilibrado:

Apto a resistir aos diversos obstáculos do meio físico e social, o que exige um exercício racional das funções de adaptação que levam ao estágio de saúde, o que é mais do que a ausência de doença. Eis a finalidade higiênica, finalidade fundamental (que a higiene e a medicina procuram atingir por meios em partes diferentes) que nunca se deveria perder de vista. (MANIFESTO MUNDIAL DE EDUCAÇÃO FÍSICA, 1971, p. 81) 
Fica evidente a atenção pedagógica para com a educação física escolar durante os anos de 1970. As preocupações existem no sentido higiênico, nas quais se buscava efetivamente um desporto para todos a fim de melhoria da saúde. A saúde foi uma das principais temáticas da educação física, aliás, desde os tempos da Antiguidade como atesta Hipócrates (2002). Sendo assim, as capacidades físicas foram evidenciadas pela sua importância nesse contexto. Realçamos que sua introdução no currículo escolar em meados do século XIX tem como referência os conhecimentos da medicina e a filosofia dos militares (nessa época os “currículos" eram variados e chamados de compêndios de ginástica).

Nesses "currículos" o desenvolvimento da saúde via aptidão física das percepções de tempo e espaço precisavam ser trabalhadas para melhorar os sentidos, bem como aprimorar as qualidades motoras básicas. Cuidar dos jovens sempre foi tarefa dos legislados, professores e dos militares, um legado indispensável para a compreensão da própria história da educação física no Brasil em busca de uma educação em saúde.

\section{Carta internacional da educação física e desportos (1978)}

Na Carta Internacional da Educação Física e Desportos (1978), da Unesco, a educação física aparece como disciplina formadora e fundamental para proporcionar valores ao ser humano. Propõe a solidariedade, respeito e fraternidade. Cita que compete aos governos o empenho no desenvolvimento humano relacionado à educação física, bem como sua responsabilidade em colocar em prática programas esportivos. Ressalta o direito à educação física na formação do caráter e tendo como objetivo o desenvolvimento da aptidão física voltada para a saúde.

Ao nível do indivíduo, a educação física e os desportos contribuem para a preservação e melhoria da saúde, bem como para o aproveitamento são dos lazeres, permitindo ao ser humano uma resistência maior aos inconvenientes da vida moderna. (CARTA INTERNACIONAL DA EDUCAÇÃO FÍSICA E DESPORTOS, 1978, p. 121)

Colocar a necessidade de uma educação física desportiva de qualidade desde a infância até o envelhecimento, levando em conta, as especificidades e as individualidades dos sujeitos é uma premissa básica da escola durante o período estudado. Já no primeiro artigo da Carta, 
o desporto e a educação física são colocados como direito fundamental para o desenvolvimento da aptidão física e da adaptação às necessidades individuais. Quanto ao ensino, o professor deve estar qualificado ao trabalho com aperfeiçoamento contínuo para encorajar a população a praticar atividades físicas e esportivas.

Sobre a pesquisa científica, esta deve fomentar uma prática racional, equilibrada e promotora de saúde. Os meios de comunicação, devendo proporcionar as massas o maior número de informações possíveis. Aos poderes públicos, não se privar do incentivo ao desporto, pois este é evidentemente educativo e saudável. Tais preocupações contidas nos documentos são também condizentes com as preocupações contidas na bibliografia da época. De Faria Junior (1972) e Negrine (1977), por exemplo, apresentam amplo conteúdo sobre higiene, aptidão física, formação integral e esporte. De Faria Junior (1972) descreve os conteúdos da educação física escolar da seguinte forma: ensino primário - relacionado à recreação, saúde ou hábitos higiênicos, harmonia corporal, aptidão física que também esta relacionada à saúde, espírito comunitário, civismo, senso moral e formação integral do caráter; ensino médio - pertinente ao aprimoramento da aptidão física, saúde, potencialidades físicas, liderança, socialização e lazer. Ensino superior - associado ao desenvolvimento e aprimoramento das práticas desportivas, buscando o sentimento de nacionalidade e da conservação da saúde. Nessa mesma linha, Negrine (1977) explica que no ensino primário devem-se desenvolver os hábitos higiênicos, desenvolvendo os aspectos mental e físico a partir do refinamento da aptidão física, assim como, do espírito comunitário criativo e cívico. No ensino médio e superior, os termos saúde, hábitos sadios e a aptidão física voltam a aparecer.

\section{DISCUSSÃO}

Ao contrário do que os críticos a respeito do período de (1964-1985) defendem, o que se observou nos documentos analisados é que a prevenção e a promoção da saúde, seja ela no formato de educação em saúde ou de recomendações, fazia parte de uma ampla exposição dos benefícios das práticas esportivas no âmbito do lazer ou escolar, dentro e fora dela (na 
sociedade de forma geral). Afastado o alto rendimento, a saúde é aplicável e até um direito como observamos na Carta Européia do Esporte para Todos (1975).

Desta maneira, é preciso saber utilizar o tempo disponível e evidentemente saber escolher as melhores opções. É preciso observar as necessidades e adequá-las ao nosso cotidiano. Já se sabe que a falta de práticas esportivas e de atividades físicas é muito perigoso. Uma vida esportiva pode ser bastante atraente, lúdica, educativa e saudável, seja ela educacional ou de lazer.

Sabemos por meio dos estudos de Tubino $(1987 ; 1999)$ que o esporte é um dos grandes fenômenos culturais da modernidade e sua ligação com a saúde, educação e lazer é tradicional. Como bem explica Tubino (1999), ao dirigir o Colégio Rugby entre 1828 a 1842, Thomas Arnold buscou a formação dos jovens ingleses agressivos e insolentes. Com o uso do termo fair-play, pelo qual significa jogo cavalheiresco ou respeito às regras, esperava-se que os jovens criassem suas próprias regras. Desta iniciativa junto ao Colégio, o espírito do fairplay ganhou proporções inimagináveis ao longo da história. No Brasil não seria diferente e nas décadas de 1964 a 1985 o modelo de educação física vai se inspirar no desenvolvimento desportivista que ocorreria em grande parte do mundo.

Antes de 1977 já era possível identificar uma série de iniciativas que poderíamos considerar como embriões do Esporte para todos (COSTA e TAKAHASHI, 1983). Na escola notaremos esta ideia de esporte e lazer nas aulas de educação física a parir do primeiro currículo de educação física do governo estadual de São Paulo (BRASIL, 1971). Deste modo, a tradição de educação física integral, esportiva e de lazer associada à saúde se ampliou durante todo o período (1964-1985).

É preciso salientar com base em Tubino (1999), e nos próprios documentos analisados aqui, que o esporte-educação e esporte-participação faziam parte do cenário internacional e chegou ao Brasil, assim como em outros países, com o intuito de contribuir na educação em saúde ou como se poderia dizer hoje, na promoção da saúde escolar. Recentemente, Garcia e Figueira Junior (2019) identificaram conteúdos relacionados ao esporte, lazer e saúde nos documentos curriculares de educação física do governo estadual de São Paulo, denominados de "Caderno do Professor" produzido em 2009. Figueira Junior e Ceschini (2018) demonstram que as práticas esportivas relacionadas à saúde são atraentes para crianças e adolescentes e que podem contribuir para a melhoria da saúde. Sabe-se, com base em Bouchard (2003) que 
as práticas de atividades físicas, entre estas, as esportivas, podem contribuir para o combate a obesidade, doença arterial coronariana (DAC) e o diabetes melito não-insulino dependente (DNID).

Vale ressaltar que o esporte é um fenômeno que transcende a perspectiva comercial e seus efeitos estão para muito além daqueles que promovem sua espetacularização com performance e alto-rendimento (atletas). 0 esporte está acessível a toda camada da população e, portanto, configura-se forte aliado à promoção da saúde e da atividade física (incluindo a prática de esporte), característica essa registrada em todo o percurso histórico da educação física no Brasil, inclusive no período ora pesquisado. Notadamente, a OMS (WHO, 2010) tem recomendado para crianças e adolescentes a prática de atividades aeróbicas (tais como atividades esportivas) com intensidade de moderada a vigorosa, três vezes por semana com tempo estimado de 60 minutos. Lembramos que o currículo do estado de São Paulo (2009) também discute e recomenda tais práticas.

\section{CONSIDERAÇÕES FINAIS}

Ao contrário do que sugere alguns autores da problemática deste artigo, o período dos governos militares (1964-1985), no Brasil, difundia via documentos internacionais os mais diversos apelos pelas práticas esportivas em benefício da saúde da população, sobretudo, na escolar ou como esporte de massa na comunidade. Os documentos são taxativos e já preconizavam muitas das discussões e preocupações que existem hoje em relação à prevenção, promoção e educação em saúde, tudo em conjunto com a família, por meio de políticas públicas, concomitantes às questões éticas e sociais.

Assim, consideramos que os documentos são condizentes com o conceito de saúde abarcando os campos físico, mental e social, e representam referencial teórico produzidos no período estudado, possibilitando a compreensão que entre os anos 1964-1985 não houve omissão da temática saúde, pelo menos na produção de pressupostos fundantes que justificavam a necessidade da prática esportiva voltada à saúde. 


\section{REFERÊNCIAS}

BOUCHARD C. Atividade física e obesidade. São Paulo: Manole; 2003.

BRASIL. Lei $\mathrm{n}^{\circ}$ 5.692, de 11 de agosto de 1971. Fixa diretrizes e bases para o ensino de $1^{\circ}$ e $2^{\circ}$ graus, e dá outras providências. Brasília - DF, 1971. Disponível em http://www.planalto.gov.br/ccivil_03/leis/l5692.htm. Acesso em 09 abr. 2020.

BRASIL. Constituição da República Federativa do Brasil: promulgada em 5 de outubro de 1988. 45. ed. São Paulo: Saraiva, 2011.

CARTA EUROPÉIA DO ESPORTE PARA TODOS (1975). (Org) TUBINO, J. M.G.; FERREIRA, V. L.C.; CAPINUSSU, J.M. HomoSportivus - Coleção Especial de Educação Física e Desportos. V. 3. Rio de Janeiro: Palestra Edições Desportivas, 1985.

CARTA INTERNACIONAL DA EDUCAÇÃO FÍSICA E DESPORTOS (1978) (Org) TUBINO, J. M.G.; FERREIRA, V. L.C.; CAPINUSSU, J.M. HomoSportivus - Coleção Especial de Educação Física e Desportos. V. 3. Rio de Janeiro: Palestra Edições Desportivas, 1985.

COSTA, L. P. D.; TAKAHASHI, G. M. Fundamentos do Esporte para Todos 1983. Rio de Janeiro: Secretaria de Educação Física e Desporto do MEC Secretaria de Educação física e Desportos, 1983.

DA COSTA, L. H.; DE SOUZA SANTOS, M.; GÓIS JUNIOR, E. G. O discurso médico e a Educação Física nas escolas (Brasil, século XIX). Revista Brasileira de Educação Física e Esporte, v. 28, n. 22; 2014, p.73-282.

DE FARIA JÚNIOR, A. G. Introdução à didática de educação física. Rio de Janeiro, Fórum Editora Ltda, 1972.

DE MELO, V. A. E.; PERES, F. DE, F. A gymnastica no tempo do Império. 1. ed. - Rio de Janeiro: 7 Letras, 2014.

FERREIRA, M. S.; NAJAR, A. L. Programas e campanhas de promoção da atividade física. Ciência \& Saúde Coletiva, 10, 207-219, 2005.

FIGUEIRA JUNIOR, A. J.; CESCHINI, F. L. Atividade Física, Esporte e Promoção da Saúde em Crianças e Adolescentes. In: Jarbas Gomes Remonte; Luis Felipe TubagiPolito. (Org.). Educação Física Escolar e Esporte de Alto Rendimento: Dá Jogo?. 1 ed. Editora Fontoura: Várzea Paulista, 2018, v. 1, p. 209-226.

GARCIA, A. B.; FIGUEIRA JUNIOR, A. Produção da saúde nos Cadernos dos Professores que integram o currículo de Educação Física do Estado de São Paulo. I Seminário da Pós-Graduação Stricto Sensu da USJT? Desafios Para Pós-Graduação Stricto Sensu. 2019.

GASSET, O. Meditação sobre a técnica. Rio de Janeiro: Instituto Liberal, 1991.

GUEDES, D. P.; GUEDES, J. E. R. P. Implementação de programas de educação física escolar direcionados à promoção da saúde. Rev. bras. Saúde esc, 3 (1-4), p. 67- 75, 1994.

HIPÓCRATES. Conhecer, cuidar, amar. O juramento e outros textos. São Paulo: Landy, 2002.

MANIFESTO MUNDIAL DA EDUCAÇÃO FÍSICA. Revista Brasileira de Educação Física e Desportos, Brasília, n. 10, p. 9-17, 1971.

MONTEIRO, P. H. N.; BIZZO, N. (2015). A saúde na escola: análise dos documentos de referência nos quarenta anos de obrigatoriedade dos programas de saúde, 1971-2011. História, Ciências, Saúde-Manguinhos, v. 22, n. 2, p. 411-428, 2015.

MONTEIRO, R. A. C. Uma Perspectiva da Lei de Diretrizes e Bases no Cotidiano Escolar. Jundiaí: Paco Editora, 2012. 
MONTEIRO, R. A. C.; GONZÁLEZ, M. L.; GARCIA, A. B. Lei de Diretrizes e Bases da Educação Nacional: o porquê e seu contexto histórico. Revista Eletrônica de Educação, v. 5, n. 2, p. 82-95. São Carlos, 2011. Disponível em http://www.reveduc.ufscar.br/index.php/reveduc/article/view/225. Acesso em 09 abr. 2020.

MOREIRA, J.C. C. Saberes em campo: a configuração do ensino escolar da educação física no Estado de São Paulo (1964-1985). Tese (Doutorado em Educação Escolar) - Universidade Estadual Paulista, Faculdade de Ciências e Letras, Campus de Araraquara, 2013.

NEGRINE, A. O ensino da educação física. Rio de Janeiro, Editora Globo, 1977.

NOEL-BAKER, P. Manifesto Mundial do Desporto. 1964. (Org)TUBINO, J. M.G.; FERREIRA, V.L.C.; CAPINUSSU, J.M. HomoSportivus - Coleção Especial de Educação Física e Desportos. V. 3. Rio de Janeiro: Palestra Edições Desportivas, 1985.

OMS. Constituição da Organização Mundial da Saúde (OMS/WHO) - 1946. (In) Universidade de São Paulo Biblioteca Virtual de Direitos Humanos. Disponível em:http://www.direitoshumanos.usp.br/index.php/OMS-Organiza\%C3\%A7\%C3\%A3o-Mundial-daSa\%C3\%BAde/constituicao-da-organizacao-mundial-da-saude-omswho.html Acesso em: 22 de janeiro 2020

PELICIONI, M. C. F.; PELICIONI, A. F. Educação e promoção da saúde: uma retrospectiva histórica. Mundo da saúde, v. 31, n 3, p. 320-328, 2007

RANKE, L. V. O conceito de história universal (1831) In. (Org) MARTINS, E. D. R. A história pensada: teoria e método na historiografia européia do Século XIX. $1^{a} \mathrm{Ed}, 2^{\mathrm{a}}$ reimpressão - São Paulo: Contexto, 2015.

SAMARA, M. S.; TUPY, I. S. S. T. História \& documento e metodologia da pesquisa. Belo Horizonte: Autêntica Editora, 2010.

SÃo PAULO. Secretaria da Educação. Centro de Estudos Humanos e Pesquisas Educacionais Prof. Laerte Ramos de Carvalho. Guias Curriculares para o ensino de $1^{\circ}$ Grau. São Paulo: CEHURP, 1973.

SÃO PAULO (Estado) Secretaria da Educação. Caderno do Professor: educação física, ensino médio - $2^{a}$ série, volume 4 / Secretaria da Educação; coordenação geral, Maria Inês Fini; equipe, Adalberto dos Santos Souza, Jocimar Daolio, Luciana Venâncio, Luiz Sanches Neto, Mauro Betti, Sérgio Roberto Silveira. - São Paulo: SSE, 2009.

TUBINO, M. G. O que é esporte? São Paulo: Brasiliense, 1999.

TUBINO, M. G. Teoria geral do esporte. São Paulo: IBRASA, 1987.

WHO, W. Global recommendations on physical activity for health. Geneva World Heal Organ, 60. 2010. Disponível em: https://www.who.int/dietphysicalactivity/global-PA-recs-2010.pdf Acesso em: 22 de janeiro 2020 .

\section{(c)) EY}

Este trabalho está licenciado com uma Licença Creative Commons - Atribuição 4.0 Internacional. 